\title{
Determinantes do voto no primeiro turno das eleições presidenciais brasileiras de 2010: uma análise exploratória
}

\begin{tabular}{c}
\hline \hline Jairo Nicolau \\
Departamento de Ciência Política \\
Instituto de Filosofia e Ciências Sociais \\
Universidade Federal do Rio de Janeiro \\
\hline \hline
\end{tabular}

\begin{abstract}
Resumo: O objetivo deste artigo é avaliar o efeito de um conjunto de variáveis no voto dos principais candidatos (Dilma Rousseff, José Serra e Marina Silva) e nos votos nulos e em branco no primeiro turno das eleições presidenciais brasileiras de 2010. A pesquisa é baseada nos resultados do Estudo Eleitoral Brasileiro (Eseb-2010). Para análise dos dados foi utilizado um modelo de regressão logística multinomial, cujos resultados são também apresentados por intermédio de gráficos com as probabilidades preditas do voto segundo algumas variáveis. Entre as variáveis selecionadas, a escolaridade, a região, a religião, a preferência partidária, o autoposicionamento na escala esquerda-direita e a avaliação de governo foram as que apresentaram diferenças na votação obtida pelos candidatos. Por outro lado, o sexo, a idade e a participação no programa Bolsa Família tiverem reduzido impacto nessa votação.
\end{abstract}

Palavras-chave: eleições presidenciais 2010; comportamento eleitoral no Brasil; voto para presidente no Brasil

\begin{abstract}
The objective of this article is to examine the effect of a set of variables on the vote of the main candidates (Dilma Rousseff, José Serra and Marina Silva), and on invalid votes in the first round of Brazilian presidential elections in 2010. The research is based on the results of "Estudo Eleitoral Brasileiro" (Brazilian Electoral Study) conducted in 2010. The data was analysed using a multinomial logistic regression model, whose results are also presented through graphics with the predicted probability. Among the selected variables, education, region, religion, party preference, self-positioning in the left-right scale and evaluation of government showed the most significant differences between the candidates. On the other hand, sex, age, and participation in the "Bolsa Família" program have limited impact on the differentiation of candidates.
\end{abstract}

Keywords: presidential elections 2010; electoral behaviour in Brazil; vote for president in Brazil

OPINIÃO PÚBLICA, Campinas, vol. 20, no 3, dezembro, 2014, p. 31 1-325 


\section{Introdução ${ }^{1}$}

A decisão do presidente Lula de escolher Dilma Rousseff para concorrer como candidata do PT à sua sucessão nas eleições de 2010 gerou muitas indagações. Qual seria a reação do eleitorado diante da primeira mulher a disputar com chances a Presidência da República. Até que ponto Lula conseguiria transferir o seu capital político, construído em três décadas de atuação, para um nome que nunca tinha disputado uma única eleição. Em que medida a distribuição dos votos de Dilma pelo território nacional se assemelharia à de Lula em eleições anteriores. Os resultados das eleições atestaram o sucesso da escolha feita pelo presidente. Além de sair vitoriosa, Dilma obteve $46,9 \%$ dos votos válidos no primeiro turno, percentual semelhante ao obtido por Lula quatro anos antes $(48,6 \%)$.

Uma comparação do padrão geográfico das votações de Lula (2006) e Dilma (2010) revela muitas semelhanças. Seus redutos eleitorais são praticamente os mesmos: o Nordeste, o estado de Amazonas e a região nordeste de Minas Gerais. Os redutos da oposição também se mantiveram: os estados de Roraima, Mato Grosso do Sul e São Paulo, a região norte do Mato Grosso, a região central do Pará e as regiões oeste do Paraná, de Santa Catarina e do Rio Grande do Sul (MARZAGÃo, 2013; Terron; SOARES, 2010).

Além de identificar as bases territoriais, um outro desafio dos estudos eleitorais é observar se determinadas características sociodemográficas, atitudes e opiniões dos eleitores estão associadas à preferência por determinado candidato. $O$ impacto de variáveis sociodemográficas e atitudinais no voto para presidente em 2010 foi tema de uma série de trabalhos (BAQUERO; GonZALES, 2011; KeRBAUY, 2011; Peixoto; Rennó, 2011; Ribeiro; Carreirão; Borba, 2011; Zucco, 2013). O mais amplo e sistemático deles (PEIXoto; RenNó, 2011) avaliou os efeitos de 13 variáveis sobre as chances de o eleitor votar em determinado candidato. Suas conclusões para os resultados do primeiro turno são as seguintes:

\footnotetext{
Quem votou em Lula em 2006, quem é simpático ao PT, quem avalia bem o governo Lula e quem percebe ter tido mobilidade social ascendente tem muito mais chance de votar em Dilma. Por outro lado, ter a cor da pele branca, ter baixa escolaridade e renda e simpatizar com o PSDB reduzem a probabilidade de votar em Dilma (PEIXOTO; RENNó, 2011, p. 315).
}

Em que pese a contribuição desses trabalhos, algumas questões sobre a escolha dos eleitores na disputa presidencial de 2010 ainda não foram respondidas: Será que o impacto de variáveis sociais, tais como a escolaridade e a religião, permanece quando uma variável contextual (a região) é introduzida na análise? Autoclassificar-se como sendo de esquerda realmente aumenta as chances de um eleitor votar em Dilma? Algum dos candidatos se beneficiou do voto dos eleitores que se definiram como sendo de direita?

O propósito deste artigo é avaliar o efeito de alguns fatores na escolha que os eleitores fizeram no primeiro turno das eleições presidenciais de 2010. Para tal, selecionei um conjunto de variáveis do banco de dados do Estudo Eleitoral Brasileiro (Eseb), pesquisa que foi a campo em 2010. O impacto de cada uma delas sobre a probabilidade de os eleitores votarem em Dilma Rousseff, José Serra, Marina Silva ou anularem/votarem em branco foi mensurado por intermédio de um modelo de regressão logística multinomial.

\footnotetext{
${ }^{1}$ Gostaria de agradecer a Dalson Britto, Eduardo Leoni, Ednaldo Ribeiro, Lilian Oliveira, Cesar Zucco Jr. e aos dois pareceristas anônimos da revista Opinião Pública os excelentes comentários à primeira versão deste artigo. Eles foram tão pertinentes que me estimularam a praticamente escrever um novo artigo.
} 


\section{Métodos}

Alguns estudos recentes têm chamado a atenção para a distinção de dois estilos de pesquisa empírica: a confirmatória e a exploratória (WAGENMAKERS et al., 2011; 2012). Na pesquisa confirmatória, mais comum em desenhos experimentais, o plano de análise e a definição de hipóteses são apresentados antes que os dados sejam coletados; ou seja, o pesquisador apresenta as suas hipóteses antes de ter acesso aos seus dados. A ideia é que o pesquisador não seja contaminado com certos tipos de vieses cognitivos, tais como o viés de confirmação e o cherry picking - prática de incluir na análise apenas as variáveis que sejam favoráveis a suas hipóteses (WAGENMAKERS et al., 2012). Já na pesquisa exploratória, o pesquisador busca encontrar padrões nos dados já coletados. Seu foco é descrever aspectos interessantes dos dados e propor modos pelos quais futuros estudos confirmam ou não resultados exploratórios.

Este artigo se filia à tradição de pesquisa eminentemente exploratória. Entre as dezenas de variáveis de um banco de dados de uma pesquisa de opinião já realizada (Eseb-2010), foram selecionadas aquelas que, no meu entender, poderiam ter algum impacto no voto para presidente. Um dos maiores desafios desse tipo de empreitada é como selecionar as variáveis. Para não cair na tentação de utilizar na análise apenas as variáveis que se mostraram estatisticamente significantes, selecionei, antes de começar a análise dos dados, um conjunto de variáveis que são tradicionalmente utilizadas pela literatura sobre comportamento eleitoral no Brasil².

\section{O Estudo Eleitoral Brasileiro - Eseb}

Para a análise de dados, utilizei os resultados do Estudo Eleitoral Brasileiro (Eseb) de 2010. A pesquisa ouviu 2.000 eleitores (indivíduos acima de 16 anos que estavam cadastrados para votar) em entrevistas domiciliares realizadas entre os dias 4 e 20 de novembro, portanto, após o segundo turno das eleições. 0 processo de seleção da amostra foi feita em três estágios: 1) seleção dos municípios pelo método PPT (probabilidade proporcional ao tamanho), tomando como base o número de moradores com 16 anos ou mais; 2) sorteio dos setores censitários ou bairros de cada município; 3) seleção dos respondentes, utilizando uma quota proporcional de gênero, idade, condição de atividade (PEA/não PEA), escolaridade e renda familiar (Cesop, 2011).

No caso específico da análise dos determinantes do voto em 2010, a amostra fica um pouco menor, já que somente os eleitores que compareceram às urnas declararam o seu voto para presidente. Com a exclusão dos eleitores que, embora inscritos, não votaram, a amostra foi reduzida para 1.862 casos.

\section{As variáveis}

A Tabela 1 apresenta um quadro com as características gerais dos eleitores, segundo os atributos das variáveis selecionadas. Com exceção da idade, todas as variáveis selecionadas são categóricas. Para a idade, os números expressam a média dos respondentes, para as outras, mostram o percentual de cada uma das categorias.

\footnotetext{
2 Entre estas, acabei excluindo algumas que não me pareceram pertinentes. Por exemplo, a renda. A razão é o alto número de não respostas e a alteração dos valores declarados por parte dos entrevistados. Aos entrevistados que se recusam a declarar a renda individual ou familiar, é oferecida a alternativa de apontar a sua faixa de renda em uma tabela. Essa opção reduz o número de não respostas, mas impede que a renda média familiar seja calculada.
} 
Tabela 1

Características dos respondentes do Eseb-2010

\begin{tabular}{|c|c|}
\hline Região & $\%$ \\
\hline Norte & 7,2 \\
\hline Nordeste & 26,9 \\
\hline Centro-Oeste & 7,5 \\
\hline Sudeste & 43,2 \\
\hline Sul & 12,0 \\
\hline \multicolumn{2}{|l|}{ Sexo } \\
\hline Homem & 48,2 \\
\hline Mulher & 51,7 \\
\hline \multicolumn{2}{|l|}{ Escolaridade } \\
\hline Fundamental incompleto & 43,8 \\
\hline Fundamental completo & 19,1 \\
\hline Ensino médio completo & 30,8 \\
\hline Ensino superior completo & 6,4 \\
\hline \multicolumn{2}{|l|}{ Religião } \\
\hline Católica & 62,1 \\
\hline Evangélica & 21,8 \\
\hline Outras & 6,5 \\
\hline Não tem, não acredita em Deus & 9,6 \\
\hline \multicolumn{2}{|l|}{ Partido } \\
\hline PT & 24,6 \\
\hline PSDB & 5,7 \\
\hline Outros & 8,6 \\
\hline Não tem partido & 61,1 \\
\hline \multicolumn{2}{|l|}{ Escala esquerda-direita } \\
\hline Esquerda & 10,7 \\
\hline Direita & 16,6 \\
\hline Centro & 29,4 \\
\hline Não sabe & 43,4 \\
\hline \multicolumn{2}{|l|}{ Avaliação do governo federal } \\
\hline Positiva & 51,1 \\
\hline Regular & 35,7 \\
\hline Negativa & 13,2 \\
\hline \multicolumn{2}{|l|}{ Beneficiário do Bolsa Família } \\
\hline Recebe & 16,4 \\
\hline Não recebe & 83,6 \\
\hline \multirow[t]{2}{*}{ Idade (média) } & \\
\hline & 40,7 \\
\hline
\end{tabular}

Um primeiro grupo de variáveis é composto por aquelas que definem atributos sociodemográficos dos entrevistados: sexo, idade, escolaridade e religião. As quatro são tradicionalmente exploradas pela literatura sobre comportamento eleitoral nas democracias tradicionais (DALTON, 2013) e nos estudos eleitorais realizados no Brasil (MARTINS JR., 2009).

Um segundo grupo é representado por variáveis que dimensionam atitudes dos eleitores em relação ao sistema político: preferência por partido político, autoposicionamento na escala esquerdadireita e avaliação do desempenho do governo federal. A preferência partidária é uma das variáveis mais testadas nos estudos sobre comportamento eleitoral no Brasil (CARREIRÃO; BARBETTA, 2004; RENNÓ, 2007; RIBEIRO; CARREIRÃo; BORBA, 2011). O Eseb-2010 fez uma série de perguntas sobre como os eleitores avaliavam os partidos políticos. Entre elas, selecionei a seguinte: "Algum partido representa a sua maneira de pensar?’3.61\% disseram que nenhum partido os representa; o PT recebeu 24\% das menções,

\footnotetext{
3 Uma das vantagens dessa pergunta é que ela só ofereceu uma opção aos eleitores. Outra pergunta feita para testar a identificação com os partidos indagou se os eleitores gostavam de algum partido, mas as respostas eram múltiplas (até três respostas); ou seja, um eleitor poderia gostar de três legendas diferentes.
} 
o PSDB, 6\%, e todos os outros partidos somados, 9\%. Em 2010, ter preferência por partido é basicamente ser petista; os eleitores do partido representavam cerca de 2/3 dos eleitores partidários.

A orientação política dos eleitores é tradicionalmente dimensionada nas pesquisas de opinião por intermédio da escala esquerda-direita. No Brasil, Singer (2000; 2012) tem chamado a atenção para a importância do posicionamento dos eleitores na escala esquerda-direita no voto para presidente. 0 Eseb-2010 solicitou aos eleitores que se posicionassem em uma escala de 11 pontos $^{4}$. Recodifiquei as respostas em três grupos: esquerda (de 0 a 3), centro (de 4 a 6) e direita (de 7 a 10). A distribuição de cada categoria foi a seguinte: $43 \%$ não souberam responder, $17 \%$ se posicionaram na direita, $29 \%$ no centro e apenas $11 \%$ na esquerda.

A avaliação do desempenho do governo tem sido apontada como uma das variáveis associadas ao sucesso (ou fracasso) do candidato governista na disputa para o Executivo no Brasil (ALMEIDA, 2008; RENNÓ, 2007). A pergunta sobre a avaliação do governo federal feita pelo Eseb-2010 ofereceu quatro opções (lidas pelo entrevistador) de resposta: ótimo, bom, ruim e péssimo. O "regular" era assinalado somente quando o eleitor espontaneamente o mencionava ${ }^{5}$. Agreguei as respostas em três grupos: avaliação positiva (ótimo e bom), negativa (ruim ou péssima) e regular. Os números de cada categoria são os seguintes: $51 \%$ de avaliação positiva, $13 \%$ de negativa e $36 \%$ de regular.

Alguns estudos baseados em macrodados mostram que os candidatos à Presidência têm recebido diferentes patamares de voto no território nacional (MARZAGÃO, 2013; SOARES; TERRON, 2008). Por conta do tamanho da amostra das pesquisas de opinião em âmbito nacional - tradicionalmente entre 1.000 e 2.000 entrevistas - não é possível fazer inferências para os estados, que são distritos eleitorais fundamentais da política brasileira. A opção para trabalhar com uma variável contextual foi incluir a região. Particularmente, para as eleições de 2010, o componente regional ganhou relevo devido à expressiva votação de Dilma na região Nordeste.

Uma última variável incluída na análise é a participação no programa Bolsa Família. Diversos estudos avaliaram os efeitos do programa no voto para presidente nas eleições de 2006 e 2010 (BoHN, 2011; Licio; Renno; Castro, 2009; Nicolau; Peixoto, 2007; Zucco, 2013). O Eseb-2010 perguntou ao entrevistado se ele participava do programa Bolsa Família. Apenas $16 \%$ responderam afirmativamente, número inferior às estimativas de famílias que recebem o benefício: em 2010, a média de famílias que receberam o benefício nos municípios brasileiros foi de 35\% ${ }^{6}$. Tal como formulada - "o Sr(a). participa do Bolsa Família?" - a pergunta pode ter dado margem a ambiguidades e contribuído para subestimar os participantes do programa, já que o indivíduo pode não receber o benefício diretamente, mas viver em uma família beneficiária.

\section{A análise estatística}

Para avaliar os efeitos das variáveis selecionadas na escolha que o eleitor fez na eleição presidencial, a opção foi utilizar um modelo de regressão logística multinomial. As categorias utilizadas

\footnotetext{
${ }^{4}$ Ao eleitor era apresentada uma escala e perguntado o seguinte: "Novamente pensando em esquerda e direta na política. Como o sr. (sra.) se considera? Zero significa que o sr. (sra.) é de esquerda e dez que o sr. (sra) é de direita".

${ }^{5} \mathrm{Na}$ pergunta em que o eleitor foi indagado sobre como avaliava o governo Lula nos últimos quatro anos, foram dadas apenas quatro opções aos respondentes: muito bom, bom, ruim e péssimo; todas lidas pelo entrevistador. Por conta da ausência da opção "regular", preferi não trabalhar com essa variável.

6 Dados calculados a partir do banco de dados organizado por Cesar Zucco Jr. Ver: <http://thedata.harvard.edu/dvn/dv/ajps/faces/study/StudyPage.xhtml?studyld=87348\&tab=files>.
} 
foram as seguintes: Dilma, Serra, Marina e votos brancos e nulos. Os outros candidatos foram excluídos da análise ${ }^{7}$.

Tradicionalmente, os resultados de um modelo de regressão logística são apresentados em uma tabela que lista os valores dos coeficientes de cada variável acompanhada pelo $p$-valor e os intervalos de confiança. Além da tabela de coeficiente, este artigo segue uma tendência recente de utilizar as probabilidades preditas pelo modelo (KASTELLEC; LEONI, 2007; KING; TOMZ; WITTENBERG, 2000). A probabilidade predita permite observar o efeito de uma (ou mais de uma) variável, mantendo as estimativas de todas as outras variáveis fixas. Assim, após calcular o modelo com todas as variáveis, é possível estimar, por exemplo, a probabilidade de os indivíduos que não completaram o ensino fundamental terem votado em Dilma. 0 passo seguinte foi apresentar as estimativas das probabilidades preditas não em tabelas, mas em um conjunto de gráficos ${ }^{8}$.

\section{Resultados}

A Tabela 2 apresenta os resultados do modelo de regressão logística para o primeiro turno. Dilma Rousseff foi selecionada como a categoria de referência para a comparação com Serra, Marina e os votos brancos e nulos. A coluna com o título "razão de risco" apresenta o resultado de estimativa de cada variável ${ }^{9}$. A razão de risco deve ser lida em comparação à categoria de base de cada variável; por exemplo, um eleitor que completou o curso fundamental tem uma probabilidade 1,6 vez maior de votar em Serra do que um eleitor com o fundamental incompleto (ver primeira coluna). As duas colunas seguintes mostram os intervalos de confiança (IC) de 95\%, inferiores e superiores, de cada estimativa. A quarta coluna apresenta o $p$-valor de cada estimativa. A mesma ordem das colunas é reproduzida para Marina e para votos brancos e nulos.

\footnotetext{
${ }^{7}$ Os candidatos são os seguintes: Plínio de Arruda Sampaio (PSOL), Rui Pimenta (PCO), José Eymael (PSDC) e Ivan Pinheiro (PCB). Somados, eles obtiveram $1 \%$ de citações na pesquisa.

${ }^{8}$ As estimativas foram calculadas por intermédio do comando "margins" do Stata (versão 13). Os gráficos foram feitos utilizando o comando "marginsplot".

${ }^{9} \mathrm{~A}$ razão de risco é também conhecida pelo termo risco relativo.
} 
NICOLAU, J. Determinantes do voto no primeiro turno das eleições presidenciais...

Tabela 2

Regressão logística multinomial

Voto para presidente no primeiro turno eleições 2010

\begin{tabular}{|c|c|c|c|c|c|c|c|c|c|c|c|c|}
\hline & \multicolumn{4}{|c|}{ Serra } & \multicolumn{4}{|c|}{ Marina } & \multicolumn{4}{|c|}{ Brancos e nulos } \\
\hline & $\begin{array}{l}\text { Razão } \\
\text { de } \\
\text { risco }\end{array}$ & $\begin{array}{c}\text { IC } \\
95 \% \\
\text { inferior }\end{array}$ & $\begin{array}{l}\text { IC 95\% } \\
\text { superior }\end{array}$ & $\begin{array}{c}\mathrm{p} \text {. } \\
\text { valor }\end{array}$ & $\begin{array}{c}\text { Razão } \\
\text { de } \\
\text { risco }\end{array}$ & $\begin{array}{l}\text { IC 95\% } \\
\text { inferior }\end{array}$ & $\begin{array}{l}\text { IC 95\% } \\
\text { superior }\end{array}$ & $p \cdot$ valor & $\begin{array}{c}\text { Razão } \\
\text { de } \\
\text { risco }\end{array}$ & $\begin{array}{l}\text { IC 95\% } \\
\text { inferior }\end{array}$ & $\begin{array}{l}\text { IC } 95 \% \\
\text { superior }\end{array}$ & $p$-valor \\
\hline \multicolumn{13}{|l|}{ Região } \\
\hline \multicolumn{13}{|l|}{$\begin{array}{c}\text { Sudeste } \\
\text { (base) }\end{array}$} \\
\hline Norte & 1.23 & 0.76 & 2.00 & 0.405 & 0.93 & 0.51 & 1.70 & 0.813 & 1.07 & 0.35 & 3.34 & 0.902 \\
\hline Nordeste & 0.65 & 0.47 & 0.91 & 0.011 & 1.04 & 0.73 & 1.49 & 0.821 & 0.63 & 0.30 & 1.33 & 0.225 \\
\hline Centro-Oeste & 1.35 & 0.84 & 2.16 & 0.218 & 0.87 & 0.49 & 1.56 & 0.643 & 0.91 & 0.33 & 2.53 & 0.857 \\
\hline Sul & 1.65 & 1.16 & 2.35 & 0.006 & 0.53 & 0.33 & 0.87 & 0.012 & 0.38 & 0.14 & 1.04 & 0.060 \\
\hline \multicolumn{13}{|l|}{ Escolaridade } \\
\hline \multicolumn{13}{|l|}{$\begin{array}{c}\begin{array}{c}\text { Fundamental } \\
\text { incomoleto }\end{array} \\
\text { ingete }\end{array}$} \\
\hline Fundamental & 1.68 & 1.18 & 2.40 & 0.004 & 2.04 & 1.29 & 3.21 & 0.002 & 1.79 & 0.75 & 4.29 & 0.193 \\
\hline Ensino médio & 1.32 & 0.94 & 1.85 & 0.109 & 3.43 & 2.29 & 5.11 & 0.000 & 3.30 & 1.60 & 6.78 & 0.001 \\
\hline Superior & 1.72 & 0.96 & 3.10 & 0.069 & 4.32 & 2.34 & 7.98 & 0.000 & 1.98 & 0.48 & 8.23 & 0.345 \\
\hline \multicolumn{13}{|l|}{ Sexo } \\
\hline \multicolumn{13}{|l|}{$\begin{array}{c}\text { Masculino } \\
\text { (base) }\end{array}$} \\
\hline Feminino & 1.10 & 0.85 & 1.42 & 0.477 & 1.27 & 0.94 & 1.72 & 0.116 & 1.04 & 0.59 & 1.84 & 0.888 \\
\hline Idade & 1.00 & 1.00 & 1.01 & 0.323 & 1.00 & 0.99 & 1.01 & 0.814 & 1.01 & 0.99 & 1.03 & 0.237 \\
\hline Religião & & & & & & & Q & & & & & \\
\hline \multicolumn{13}{|l|}{ Católica } \\
\hline Evangélica & 1.44 & 1.04 & 1.98 & 0.027 & 3.49 & 2.47 & 4.95 & 0.000 & 2.17 & 1.09 & 4.34 & 0.028 \\
\hline Outras & 0.86 & 0.50 & 1.50 & 0.602 & 1.27 & 0.69 & 2.31 & 0.444 & 4.20 & 1.78 & 9.90 & 0.001 \\
\hline Não tem & 0.93 & 0.59 & 1.46 & 0.752 & 1.35 & 0.82 & 2.23 & 0.238 & 1.70 & 0.70 & 4.10 & 0.239 \\
\hline \multicolumn{13}{|l|}{ Partido } \\
\hline PT & 0.15 & 0.10 & 0.22 & 0.000 & 0.28 & 0.19 & 0.41 & 0.000 & 0.16 & 0.06 & 0.43 & 0.000 \\
\hline PSDB & 11.02 & 5.17 & 23.48 & 0.000 & 3.09 & 1.22 & 7.81 & 0.017 & 2.40 & 0.48 & 12.09 & 0.289 \\
\hline Outros & 1.57 & 0.97 & 2.54 & 0.065 & 4.32 & 2.69 & 6.93 & 0.000 & 0.58 & 0.13 & 2.59 & 0.480 \\
\hline $\begin{array}{c}\text { Não tem } \\
\text { Dartido (base) }\end{array}$ & 1.00 & & & & 1.00 & & & & 1.00 & & & \\
\hline \multicolumn{13}{|l|}{$\begin{array}{l}\text { Escala } \\
\text { esquerda- } \\
\text { direita }\end{array}$} \\
\hline Esquerda & 0.42 & 0.25 & 0.70 & 0.001 & 1.09 & 0.66 & 1.80 & 0.749 & 0.08 & 0.01 & 0.64 & 0.017 \\
\hline Centro & 1.00 & 0.69 & 1.46 & 0.986 & 1.76 & 1.15 & 2.68 & 0.009 & 0.86 & 0.41 & 1.80 & 0.686 \\
\hline Direita & 1.40 & 1.03 & 1.90 & 0.029 & 1.32 & 0.91 & 1.92 & 0.144 & 0.33 & 0.14 & 0.77 & 0.011 \\
\hline 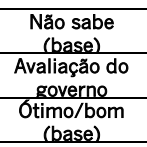 & & & & & & & & & & & & \\
\hline Regular & 1.48 & 1.13 & 1.94 & 0.004 & 1.45 & 1.05 & 1.99 & 0.023 & 2.73 & 1.41 & 5.28 & 0.003 \\
\hline Ruim/péssimo & 2.09 & 1.40 & 3.12 & 0.000 & 2.56 & 1.64 & 4.01 & 0.000 & 7.10 & 3.33 & 15.16 & 0.000 \\
\hline \multicolumn{13}{|l|}{ Bolsa Família } \\
\hline Recebe & 1.01 & 0.71 & 1.44 & 0.970 & 0.63 & 0.40 & 1.01 & 0.057 & 0.71 & 0.28 & 1.81 & 0.475 \\
\hline \multicolumn{13}{|l|}{$\begin{array}{c}\text { Não recebe } \\
\text { (base) }\end{array}$} \\
\hline Constante & 0.35 & 0.19 & 0.63 & 0.000 & 0.10 & 0.05 & 0.20 & 0.000 & 0.02 & 0.01 & 0.09 & 0.000 \\
\hline
\end{tabular}

* Dilma é utilizada como categoria de referência. Nota: $\mathrm{N}=1.731$. Pseudo $\mathrm{R}^{2}=0.176$ 
Existem duas formas de dimensionar os efeitos das variáveis selecionadas sobre o voto para presidente. A primeira é observar o p-valor. quanto mais próximo de zero, menor é a probabilidade de que os efeitos obtidos no modelo sejam mero fruto do acaso, sendo, assim, estatisticamente significantes. A segunda é observar os intervalos de confiança de uma estimativa, que devem variar apenas entre valores abaixo de 1 ou acima de 1 . A razão é simples: uma estimativa não pode variar da probabilidade de ocorrer (acima de 1) para a probabilidade de não ocorrer (abaixo de 1). Por isso, as bandas de variação do intervalo de confiança devem operar abaixo de 1 ou acima de 1 . Quando a variação ultrapassa o patamar de 1 , é sinal de que elas não são estatisticamente significantes.

Sabemos que o fator regional foi importante nas eleições de 2010, particularmente por conta da votação expressiva obtida pela candidata do PT na região Nordeste $(62 \%$ dos votos válidos no primeiro turno). O desafio era observar se o efeito regional se mantém quando características dos eleitores são incorporadas à análise. Os dados da Tabela 2 mostram que as regiões Nordeste e Sul afetaram o resultado das eleições na comparação entre Dilma e Serra. Mantidos constantes os efeitos de todas as outras variáveis, morar no Nordeste é um fator que aumenta a probabilidade do voto em Dilma e diminui a probabilidade do voto em Serra. Já para o Sul, os resultados se invertem: residir na região é um fator que aumenta a probabilidade do voto em Serra e diminui a do voto em Dilma.

Entre as variáveis sociodemográficas selecionadas, duas apresentam valores estatisticamente significantes (escolaridade e religião) e outras duas não (idade e sexo). Pelo fato de Dilma ser a primeira mulher a concorrer para presidente com chances reais de vitória, havia expectativa de que ela tivesse ampla votação entre as mulheres. Embora não seja estatisticamente significante, o efeito do sexo sobre o voto ocorreu na direção contrária do esperado: ser mulher diminui a probabilidade do voto em Dilma e aumenta a probabilidade do voto em Serra.

As três variáveis que mensuram atitudes políticas - classificação na escala esquerda-direita, partido e avaliação do governo - são estatisticamente significantes. Preferir o PT, classificar-se na esquerda da escala e avaliar positivamente o governo são fatores que aumentam expressivamente a probabilidade do voto em Dilma e diminuem a do voto em Serra.

Um resultado que chama a atenção é o fato de o Bolsa Família não aparecer como uma variável estatisticamente significante. Diante da importância do programa para o governo Lula, a expectativa era de que ser beneficiário do programa tivesse um efeito decisivo para as chances do voto em Dilma.

As probabilidades preditas

As probabilidades preditas foram calculadas para as seis variáveis que apresentaram resultados estatisticamente significantes. Para facilitar a visualização, os resultados são apresentados graficamente (ver Figuras de 1 a 6). As estimativas aparecem nos círculos, com as barras laterais indicando as margens de erro - com o intervalo de confiança de 95\%. Os dados apresentados desse modo permitem ao leitor observar as diferenças entre os candidatos, bem como as diferenças das categorias para cada candidato. No caso das categorias de cada candidato (observação de um único gráfico), é importante perceber quando as barras não ficam justapostas, indicando que as diferenças estão fora da margem de erro.

A Figura 1 mostra a probabilidade predita segundo a região. Os gráficos individuais revelam uma razoável estabilidade; com exceção da comparação Nordeste-Sul para Serra e Marina. A observação 
do gráfico das probabilidades preditas para Dilma mostra que as diferenças entre as regiões não são expressivas.

Figura 1

Probabilidade predita (IC de 95\%) segundo a região Turno 1

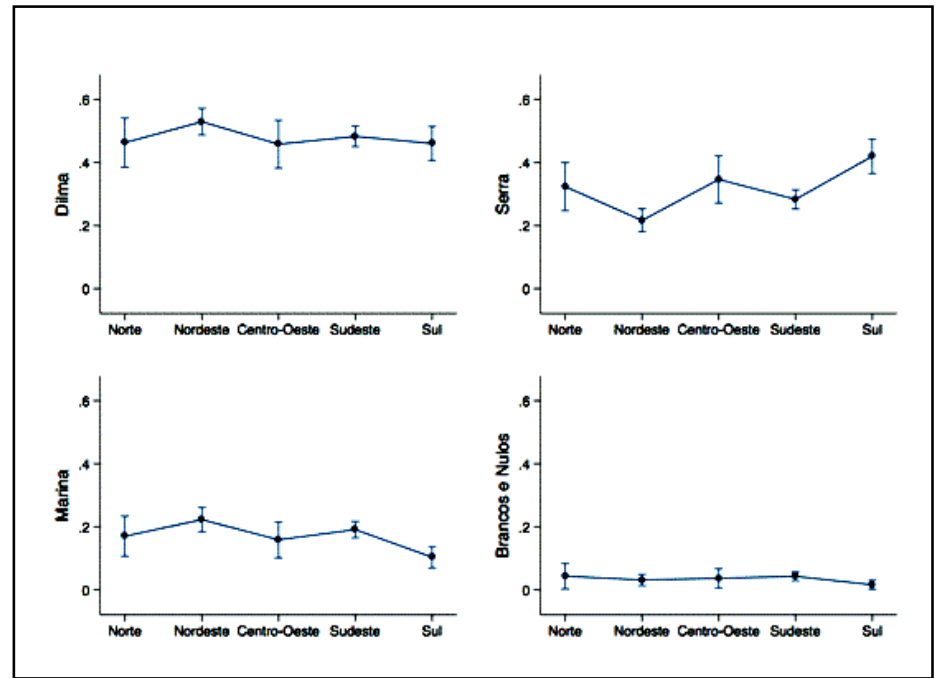

Fonte: Elaboração própria a partir do banco de dados do Eseb-2010; $\mathrm{n}=1.862$.

Os efeitos da escolaridade são apresentados na Figura 2. Chama a atenção a inversão das linhas, quando se comparam os gráficos de Dilma e Marina. A probabilidade de voto em Dilma cai à medida que aumenta a faixa de escolaridade (com expressiva diferença entre os eleitores que não acabaram o fundamental e os outros), enquanto para Marina ocorre o contrário: a probabilidade de voto aumenta nas faixas de maior escolaridade. Para Serra, não há diferenças relevantes entre os segmentos educacionais.

Figura 2

Probabilidade predita (IC de 95\%) segundo a escolaridade

Turno 1

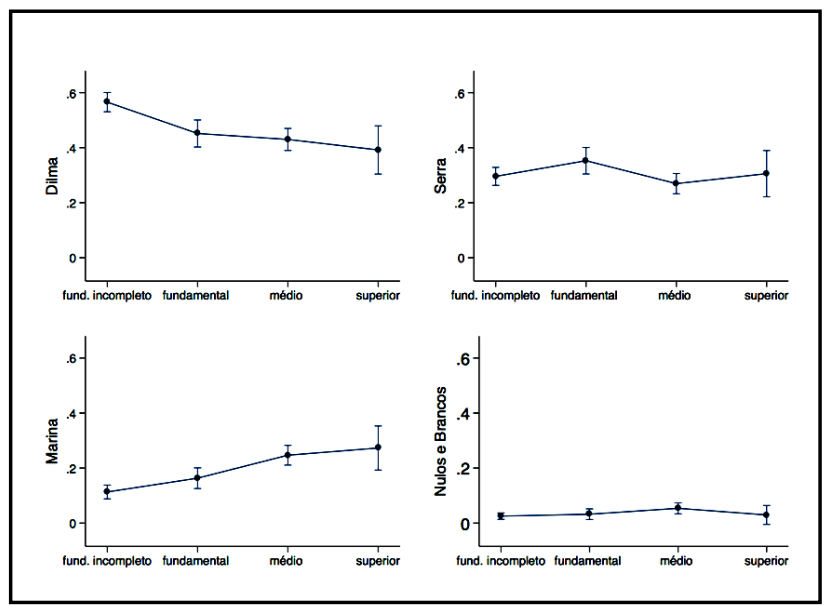

Fonte: Elaboração própria a partir do banco de dados do Eseb-2010; $n=1.862$. 
A Figura 3 apresenta os efeitos da religião. Novamente, o contraste mais relevante ocorre na comparação entre Dilma e Marina. A probabilidade do voto em Dilma é muito menor entre os evangélicos do que entre os católicos, os que pertencem a outra denominação religiosa e os que não têm religião. Para Serra, não há diferença expressiva entre os diversos segmentos religiosos.

Figura 3

Probabilidade predita (IC de 95\%) segundo a religião

Turno 1

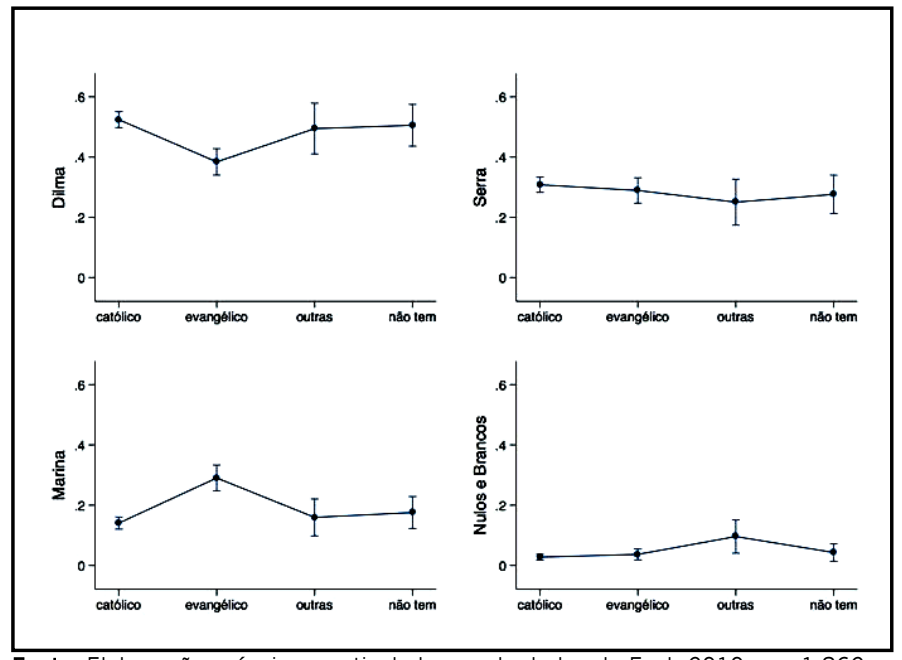

Fonte: Elaboração própria a partir do banco de dados do Eseb-2010; n = 1.862

As Figuras de 4 a 6 apresentam os efeitos das variáveis que medem as atitudes políticas. A Figura 4 mostra a probabilidade de voto para presidente, segundo o partido preferido dos eleitores. Ter preferência pelo PT ou pelo PSDB é um fator fortemente associado à probabilidade do voto, respectivamente, em Dilma ou em Serra. Para Marina, a maior probabilidade de voto ocorre entre os eleitores com preferência por outros partidos (entre eles, o PV, partido pelo qual ela concorreu). 
Figura 4

Probabilidade predita (IC de 95\%) segundo o partido

Turno 1

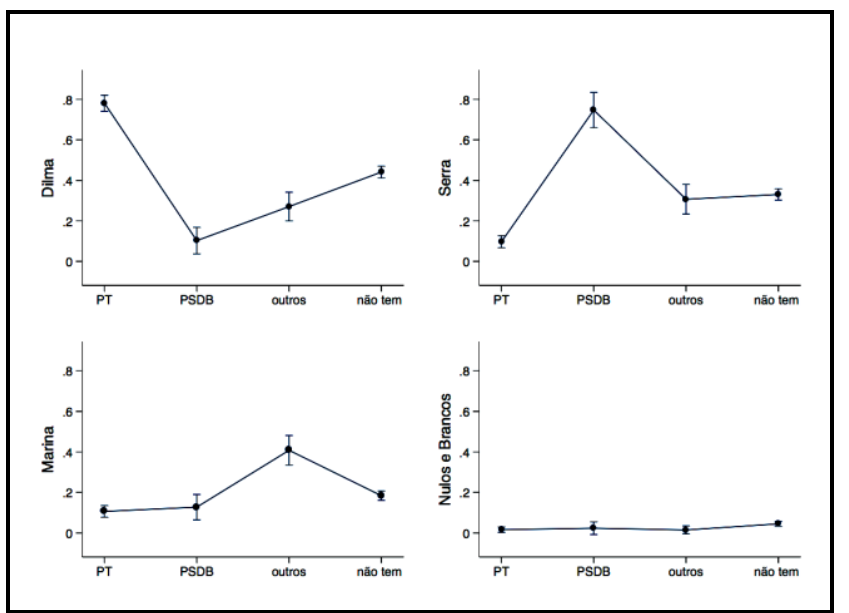

Fonte: Elaboração própria a partir do banco de dados do Eseb-2010; $n=1.862$

O efeito da autoclassificação na escala esquerda-direita é apresentado na Figura 5. A probabilidade do voto em Dilma é maior entre os eleitores que se colocaram à esquerda, mas não há diferenças relevantes entre as outras categorias. Já para Serra a probabilidade aumenta da esquerda para direita. A comparação entre os gráficos de Serra e Dilma revela que a probabilidade do voto em Dilma é maior entre os eleitores de centro e direita, embora neste último caso as diferenças sejam pequenas.

Figura 5

Probabilidade predita (IC de 95\%) segundo escala esquerda-direita Turno 1
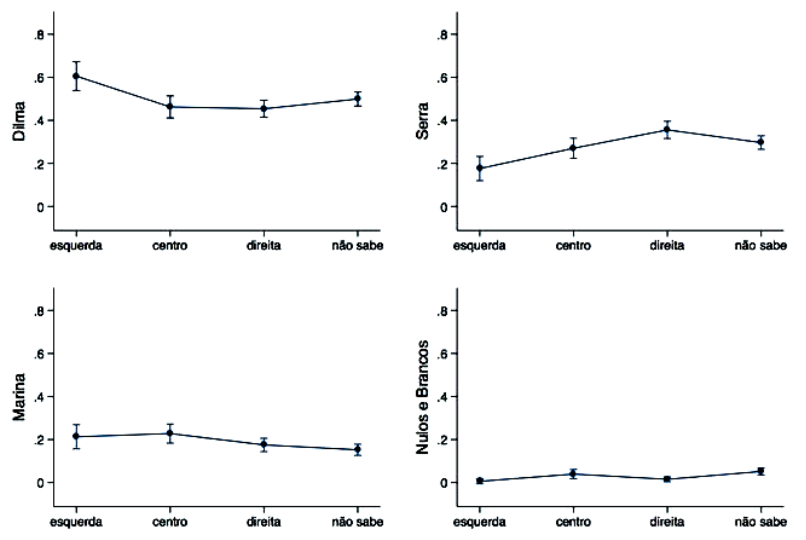

Fonte: Elaboração própria a partir do banco de dados do Eseb-2010; $n=1.862$. 
A Figura 6 mostra a probabilidade predita do voto para presidente, segundo a avaliação do governo. Os resultados são convergentes com a expectativa: a probabilidade de votar em Dilma é maior entre os eleitores que avaliam o governo federal positivamente e declina entre os que consideram o governo regular, e cai ainda mais entre os que dão avaliação negativa. O que surpreende é que a probabilidade de votar em Dilma é maior mesmo entre os candidatos que avaliaram o governo de maneira negativa.

Figura 6

Probabilidade predita (IC de 95\%) segundo a avaliação do governo Turno 1
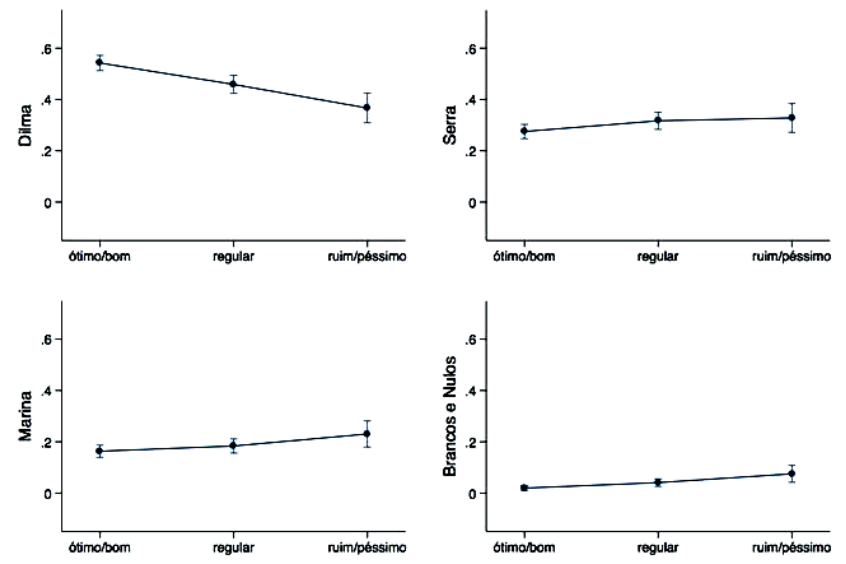

Fonte: Elaboração própria a partir do banco de dados do Eseb-2010; $\mathrm{n}=1.862$

\section{Discussão}

Afinal, que fatores foram mais decisivos nas probabilidades de votar em determinado candidato no primeiro turno das eleições presidenciais de 2010? Entre as variáveis sociodemográficas, a escolaridade e a religião foram as que tiveram o impacto mais expressivo. A escolaridade já havia aparecido como um fator relevante para distinguir o voto nos candidatos nas eleições de 2002 e 2006 (Nicolau, 2007; RenNo, 2007) ${ }^{10}$. Por intermédio das probabilidades preditas (Figura 2) os efeitos da escolaridade podem ser observados de maneira mais clara. Vale a pena destacar os gráficos de Dilma e Marina, que apresentam padrões inversos: a probabilidade do voto em Dilma cai à medida que se aumenta o segmento escolar, enquanto a do voto em Marina aumenta.

O efeito da religião também foi importante no contraste entre Dilma e Marina. Entre os evangélicos, a probabilidade de votar em Marina cresce, enquanto a de votar em Dilma diminui. 0 vínculo de Marina com as denominações evangélicas provavelmente foi um fator decisivo para a sua votação nesse segmento, como já havia acontecido nas eleições de 2002 com a candidatura de Garotinho. $\mathrm{O}$ que está ainda em aberto é se o efeito da religião sobre o voto é dependente da presença de

10 Para 2010, os efeitos da escolaridade não foram apontados como estatisticamente significantes para o voto em Dilma (PEIXoto; RenNó, 2011). 
candidatos evangélicos na disputa, ou passou a ser um fator mais estrutural do comportamento eleitoral no Brasil.

Por conta da importância da religião e da escolaridade como fatores que afetam o voto presidencial no Brasil, pesquisas de opinião futuras devem aperfeiçoar as perguntas sobre o tema. É fundamental perguntar não apenas até que faixa escolar o entrevistado cursou, mas ter a informação mais precisa de qual foi sua série final na escola. Com relação à denominação religiosa, o desafio é conseguir capturar as diferenças entre as diversas igrejas evangélicas, bem como observar se o padrão de comparecimento aos cultos é um fator importante.

Nas eleições de 2006 e 2010, as diferenças de voto entre os estados passaram a ser um fator importante para distinguir o desempenho dos candidatos, de maneira mais intensa do que nas eleições anteriores. Pelo fato de o Eseb-2010 entrevistar 2.000 eleitores, selecionados em uma amostra nacional, não foi possível mensurar o peso específico do "fator estadual" no voto para presidente. A inclusão da região na análise teve efeitos menos intensos do que o esperado. A Figura 1 mostra que, na presença dos fatores selecionados, o peso da variável "região" praticamente desaparece; exceção para a região Sul, onde Serra tem a sua maior probabilidade de ser votado e Marina, sua menor probabilidade. A solução para avaliar o impacto dos estados (ou pelo menos dos maiores) simultaneamente a fatores de natureza individual seria aumentar a amostra nacional, com a eventual sobrerrepresentação de alguns estados.

Em contraste com as variáveis sociodemográficas, as três variáveis associadas a atitudes políticas dos eleitores apresentaram efeitos muito mais expressivos na comparação entre os dois principais candidatos. O efeito da identificação partidária no voto para presidente é basicamente circunscrito às duas legendas que têm polarizado as disputas presidenciais no país: um eleitor simpático ao PT tem alta probabilidade de votar em Dilma e não votar em Serra, enquanto um eleitor simpático ao PSDB tem alta probabilidade de votar em Serra e não votar em Dilma.

Os efeitos da identificação partidária, fator relevante nos estudos eleitorais de diversas democracias, devem ser vistos com alguns cuidados no Brasil, por uma série de razões. A primeira delas é o papel fundamental do PT na opinião pública. Falar em efeito da identificação partidária no Brasil é praticamente falar dos efeitos do petismo. O segundo cuidado é que a identificação partidária não é uma variável totalmente independente em relação ao voto para presidente. Eleitores que preferem um determinado candidato a presidente acabam "preferindo" o partido ao qual este pertence. Por isso, é comum que partidos que apresentam candidatos para o Executivo cheguem ao fim da campanha com uma taxa de identificação partidária mais alta ${ }^{11}$.

Até que ponto a distinção da escala esquerda-direita foi importante na disputa presidencial de 2010? Um fato que chama a atenção é que a probabilidade de voto em Dilma é alta mesmo entre os eleitores que se classificam no centro, na direita ou não responderam. 0 aspecto relevante na distinção entre Dilma e Serra é o posicionamento à esquerda: nesse caso, a probabilidade do voto em Dilma é bem maior e do voto em Serra é bem menor. Para dimensionar o impacto global desse fator, é importante lembrar que os eleitores de esquerda representam apenas $11 \%$ do total.

Nos estudos eleitorais feitos no Brasil, a escala esquerda-direita é tradicionalmente recodificada durante a análise para se tornar uma variável categórica. Por essa razão, minha sugestão é

\footnotetext{
${ }^{11}$ A única pesquisa de painel feita no Brasil em âmbito nacional mostrou que os partidos que apresentam candidatos a presidente aumentam o índice de identificação partidária ao longo da campanha (AmEs et al., 2013, p. 15).
} 
que pesquisas futuras devessem utilizar, além da tradicional escala numérica, uma com atributos nominais; por exemplo, esquerda, centro-esquerda, centro, centro-direita e direita.

Um dos resultados que mais chamaram a atenção no modelo proposto foi o fato de o programa Bolsa Família não ter aparecido como uma variável estatisticamente significante. Existem algumas possíveis explicações para esse "não efeito". Uma delas é a alta concentração de beneficiários do programa entre os indivíduos de baixa escolaridade (na amostra, 64\% dos beneficiários têm fundamental incompleto e nenhum tem curso superior). Ou seja, a forte associação entre baixa escolaridade e os beneficiários do Bolsa Família pode ter reduzido o efeito desta no modelo. Outro fator que pode ter afetado o resultado é a forma como a questão foi formulada no Eseb-2010. A pergunta direta se o respondente era beneficiário, sem incluir outro morador da residência, provavelmente subestimou o número de beneficiários na amostra, e, consequentemente, pode ter afetado a estimativa estatística.

O efeito da avaliação do governo sobre o voto é convergente com as expectativas: a probabilidade do voto em Dilma é maior entre os que avaliam o governo positivamente e declina entre os que o avaliam de maneira negativa; o inverso ocorre com Serra. O que intriga é que, quando controlado pelo efeito de outras variáveis, a probabilidade do voto em Dilma é alta mesmo entre os eleitores que consideram o governo ruim ou péssimo. Esses resultados sugerem duas questões: Por que esses eleitores votariam na candidata do governo e não na oposição? Será que, quando descolado da figura do chefe do Executivo, o voto retrospectivo não perderia uma parte dos seus efeitos?

No começo do artigo salientei o caráter exploratório deste artigo. A ideia foi explorar os efeitos das variáveis selecionadas sobre a probabilidade do voto em um dos candidatos que disputaram a Presidência em 2010. A utilização de um modelo multivariado permitiu avaliar os efeitos de cada uma dessas variáveis, mostrando que algumas delas realmente foram importantes para distinguir os candidatos.

Para pesquisas futuras, dois desafios estão postos. O primeiro é aperfeiçoar algumas perguntas, com objetivo de captar melhor determinadas sutilezas do comportamento eleitoral brasileiro. O segundo é ampliar o leque de questões para dimensionar o papel dos atributos dos candidatos (carisma, competência, liderança) na escolha eleitoral.

\section{Referências Bibliográficas}

ALmeIDA, A. A cabeça do eleitor: estratégia de campanha, pesquisa e vitória eleitoral. Rio de Janeiro: Record, 2008.

AMEs, B. et al. The Brazilian electoral panel studies (Beps): Brazilian public opinion in the 2010 presidential elections. Inter-American Development Bank, 2013.

Baquero, M.; Gonzalez, R. S. "Eleições, estabilidade democrática e socialização política no Brasil: análise longitudinal da persistência de valores nas eleições presidenciais de 2002 a 2010". Opinião Pública, vol. 17, n 2, p. 369.399, 2011.

Boнn, S. R. "Social policy and vote in Brazil: Bolsa Família and the shifts in Lula's electoral base". Latin American Research Review, vol. 46, n’1, p. 54-69, 2011.

CARreiRÃo, Y.; BarbetTA, P. A. "A eleição presidencial de 2002: a decisão do voto na região da grande São Paulo". Revista Brasileira de Ciências Sociais, vol. 19, n 56, 2004.

Cesop. Encarte Tendências. Opinião Pública, vol. 17, n² 2, p. 516-540, nov. 2011.

DaLton, R. J. Citizen politics: public opinion and political parties in advanced industrial democracies. 6. ed. London: Cq Press, 2013. 
Kastellec, J. P.; LeONI, E. L. "Using graphs instead of tables in political science". PPS, vol. 5, n 4, 28 nov. 2007.

KeRBaUy, M. T. M. "Os programas de transferência de renda e o voto regional nas eleições presidenciais de 2010". Opinião Pública, vol. 17, n² 2, p. 477.492, 2011.

KING, G.; Tomz, M.; WiTTEnBeRG, J. "Making the most of statistical analyses: improving interpretation and presentation". American Journal of Political Science, vol. 44, $n^{\circ} 2$, p. 341-355, 2000.

Licio, E. C.; Rennó, L.; CAStro, H. C. O. "Bolsa Família e voto na eleição presidencial de 2006: em busca do elo perdido". Opinião Pública, vol. 15, n² 1, p. 31.54, 2009.

MARTInS JR., J. P. "Modelo sociológico de decisão de voto presidencial no Brasil 1994-2006". Revista Debates, vol. 3, nº 2, p. 68-96, jul.-dez. 2009.

MARZAgão, T. "A dimensão geográfica das eleições brasileiras". Opinião Pública, vol. 19, n² 2, p. 270-290, 2013.

Nicolau, J. "An analysis of the 2002 presidential elections using logistic regression". Brazilian Political Science Review, vol. $1, \mathrm{n}^{\circ} 1$, p. $125 \cdot 135,2007$.

Nicolau, J.; Peixoto, V. Uma disputa em três tempos: uma análise das bases municipais nas eleições presidenciais de 2006. In: Anais XXI Encontro Anual da Anpocs, 20 set. 2007.

Peixoto, V.; Rennó, L. "Mobilidade social ascendente e voto: as eleições presidenciais de 2010 no Brasil". Opinião Pública, vol. 17, n² 2, p. 304-332, 2011.

RenNó, L. "Escândalos e voto: as eleições presidenciais brasileiras de 2006". Opinião Pública, vol. 13, n² 2, p. 260-282, 2007 .

Ribeiro, E.; CarreirÃo, Y.; Borba, J. "Sentimentos partidários e atitudes políticas entre os brasileiros". Opinião Pública, vol. 17, n², p. 336-368, 2011.

SINGER, A. Esquerda e direita no eleitorado brasileiro: a identificação ideológica nas disputas presidenciais de 1989 e 1994. São Paulo: Edusp, 2000.

Os sentidos do lulismo: reforma gradual e pacto conservador. São Paulo: Cia. das Letras, 2012.

SOARES, G. A. D.; TeRRON, S. "Dois Lulas: a geografia eleitoral da reeleição (explorando conceitos, métodos e técnicas de análise geoespacial)". Opinião Pública, vol. 14, n², p. 269-301, 2008.

Terron, S.; SoARes, G. A. D. "As bases eleitorais de Lula e do PT: do distanciamento ao divórcio". Opinião Pública, vol. $16, \mathrm{n}^{\circ}$ 2, p. 310-337, 2010.

WAGENMAKERS, E. J. et al. "Why psychologists must change the way they analyze their data: the case of psi: comment on Bem (2011)". Journal of Personality and Social Psychology, vol. 100, n 3, p. 426-432, 2011.

Wagenmakers, E. J. et al. "An agenda for purely confirmatory research". Perspectives on Psychological Science, vol. 7, $n^{\circ} 6$, p. $632 \cdot 638,7$ nov. 2012

ZUcco JR., C. "When payouts pay off: conditional cash transfers and voting behavior in Brazil 2002-10". American Journal of Political Science, vol. 57, n 4, p. 810-822, out. 2013.

Jairo Nicolau - jaironicolau@gmail.com

Submetido à publicação em outubro de 2013.

Versão final aprovada em julho de 2014. 